\title{
Assessment of cognitive impairment in patients with Parkinson's disease: prevalence and risk factors
}

\author{
Qiumei Wang' \\ Zhenxin Zhang ${ }^{2}$ \\ Ling $\mathrm{Li}^{2}$ \\ Hongbo Wen ${ }^{2}$ \\ Qun $X u^{3,4}$ \\ 'Department of Geriatrics, \\ ${ }^{2}$ Department of Neurology, ${ }^{3}$ School of \\ Basic Medicine, Peking Union Medical \\ College Hospital, ${ }^{4}$ Department of \\ Epidemiology and Biostatistics, \\ Institute of Basic Medical Sciences, \\ Chinese Academy of Medical Sciences, \\ Beijing, People's Republic of China
}

Correspondence: Zhenxin Zhang Department of Neurology, Peking Union Medical College Hospital, Chinese Academy of Medical Sciences, Beijing 100730, People's Republic of China

Tel +861069154063

Fax +86 I0 69154063

Email zhangzhenxin2013@|26.com
This article was published in the following Dove Press journal:

Clinical Interventions in Aging

12 February 2014

Number of times this article has been viewed

Background: Although Parkinson's disease (PD) is clinically characterized by motor symptoms, cognitive impairment is one of the most disabling non-motor symptoms. Despite it attracting increasing attention worldwide, less is known about its prevalence in the Chinese population. The objective of this study was to assess cognitive impairment and related risk factors in Chinese PD patients.

Methods: We collected the demographic, diagnostic, and treatment information of 901 PD patients from 42 centers throughout the People's Republic of China, then administered a battery of neuropsychological tests, to assess motor, cognitive, and neuropsychiatric symptoms.

Results: Overall, 193 of 901 (21.4\%) PD patients met the criteria for dementia (PD-D), and $206(22.8 \%)$ met the criteria for mild cognitive impairment (PD-MCI). Visuospatial dysfunction and attention/executive impairment predominated. Increased severity of cognitive impairment was associated with greater motor impairment. Patients with psychiatric symptoms, such as depression and hallucinations, were more likely to have dementia. Potentially, the younger-aged and more educated are shown less cognitive impairment, but age at onset, and levodopa equivalent dose, were not associated with the presence of cognitive dysfunction.

Conclusion: The prevalence and profile of cognitive impairment in Chinese PD patients, as well as the risk factors, are similar as those reported for other races, but the frequency of nonamnestic cognitive domains differs.

Keywords: cognitive impairment, risk factor, prevalence, Parkinson's disease

\section{Introduction}

Cognitive impairment is one of the most common and disabling non-motor symptoms in Parkinson's disease (PD), yet it is not routinely treated in clinical practice. The prevalence of PD-related cognitive impairment varies greatly across studies. Moreover, although overt dementia in PD patients (PD-D) has been extensively investigated, ${ }^{1}$ and specific diagnostic criteria have been developed, ${ }^{2}$ there is no established diagnosis criteria for subtler impairment in PD patients. ${ }^{3}$

Our understanding of cognitive impairment and dementia in the Chinese PD population is particularly limited. Two small-scale studies, ${ }^{4,5}$ and reviews of the literature on all non-motor symptoms, ${ }^{6}$ have revealed that Chinese PD patients suffer from nonmotor symptoms, but there appear to be some differences, compared with prevalence rates and risk factors for these symptoms within Western populations. ${ }^{6}$ Notably, there is no epidemiological data on cognitive impairment from a large sample of Chinese patients. Therefore, we recruited a series of PD patients, to investigate the frequency 
and profiles of cognitive impairment, and to assess possible predictive risk factors, within this population.

\section{Patients and methods}

\section{Patients and study instruments}

A total of 901 PD patients were recruited from 42 universityaffiliated hospitals throughout seven cities in The People's Republic of China from December 2005 to January 2008. All relevant information from patients in each hospital was recorded. Patients were then examined using a standardized interview documents on demographic, diagnostic, and treatment information, along with a three-part assessment battery. This study was approved by the institutional review boards of the relevant hospitals, and written informed consent was obtained from every patient selected.

The neuropsychological examination comprised three parts. Section A consisted of patient demographics, including age, gender, education, occupation, and living situation. Section B documented diagnostic and treatment information, and data regarding the onset and symptoms of PD. Section $\mathrm{C}$ comprised four scales for rating symptoms. The motor and related symptoms battery contained the Hoehn and Yahr Scale (HY), ${ }^{7}$ Part I (Mentation, Behavior, and Mood), Part II (Activities of Daily Living), and Part IV (Complications) of the Unified PD Rating Scale (UPDRS). ${ }^{8}$ The cognitive battery contained the Chinese version of the Mini Mental State Exam (C-MMSE) (30 maximum) and the Montreal Cognitive Assessment (MoCA) (30 maximum). Additionally, all patients were assessed using standard cognitive tests: the Fuld Object Memory Evaluation (0-20 points), to assess the memory domain, the Fuld Verbal Fluency test (FVFT), to evaluate verbal ability, the revised Wechsler Intelligence Scale for Children (WISC-R) Block Design (62 maximum), to assess visuospatial function, the revised Wechsler Adult Intelligence Scale (WAIS-R) Digit Span (22 points), to evaluate attention, and the seventeen-item Hamilton Depression Rating Scale with 17 items (Hdrs-17) and Neuropsychiatric Inventory (NPI), to evaluate behavior and mood. Cut-offs for determination of cognitive impairment were based on individual education levels.

We included only cases of PD with clinical onset before the starting date of the survey. We employed a standardized diagnostic appraisal for all patients, which followed the UK Parkinson's Disease Society Brain Bank Criteria for idiopathic PD. A principal investigator reconfirmed all assessments, after regional supervisors had made diagnoses using all available information from each center. The diagnosis of probable PD with dementia (PD-D) was made using criteria recommended by the Movement Disorder Society. ${ }^{2}$ PD patients with mild cognitive impairment (PD-MCI) were not clinically demented, but were impaired in any one of four cognitive domains: attention, executive function, visuospatial function, and free-recall memory.

\section{Data analyses}

Data are expressed as means with standard deviations (SD) for normal distributions. We used chi-square tests for nominal variables, and Fisher's Exact tests for quantitative variables. Logistic regression analyses were performed to evaluate categorical predictor variables for PD-D and PD-MCI. Odds ratios (OR) and 95\% confidence intervals (CI) were reported. Differences were considered statistically significant at $P<0.05$. Analyses were performed using SAS version 8.0 statistical software (SAS Institute Inc., Cary, NC, USA).

\section{Results}

\section{Patient characteristics}

A total of 901 consecutive patients met the UK Parkinson's Disease Society Brain Bank Criteria for idiopathic PD; a total of 18 patients were excluded because of symptoms suggesting atypical parkinsonism $(n=12)$, and overlapping enrollment with different centers $(n=6)$. There were 562 (62.4\%) men. The average age was $65.4 \pm 10.7$ years (Table 1 ). The average duration of PD in this sample was $5.5 \pm 4.5$ years. According to the HY scale, $19.2 \%, 62.2 \%$, and $18.6 \%$ were at Stages I, II, and III or higher, respectively.

Table I Patient characteristics

\begin{tabular}{ll}
\hline Characteristic & 90 I \\
Patients, $\mathrm{n}$ & $562(62.4)$ \\
Men, $\mathrm{n}(\%)$ & $65.4 \pm 10.7$ \\
Age (mean \pm SD, years) & $10.7 \pm 4.6$ \\
Education (mean \pm SD, years) & \\
Occupation, $\mathrm{n}(\%)$ & $392(43.5)$ \\
$\quad$ Laborers/service workers & $253(28.1)$ \\
Administrators & $256(28.4)$ \\
Professionals & $722(80.1)$ \\
Financially independent, $\mathrm{n}(\%)$ & $60.0 \pm 1 \mathrm{I} . \mathrm{I}$ \\
Age at PD onset (mean \pm SD years) & $5.5 \pm 4.5$ \\
PD duration (mean \pm SD years) & \\
Duration (onset to first visit) & $542(60.2)$ \\
$\leq 6$ years & $236(26.2)$ \\
7-24 years & $123(13.6)$ \\
$>24$ years & \\
HY stage, $\mathrm{n}(\%)$ & $173(19.2)$ \\
Stage I & $560(62.2)$ \\
Stage II & $168(18.6)$ \\
Stage $\geq I I I$ &
\end{tabular}

Abbreviations: PD, Parkinson's disease; SD, standard deviation; HY, Hoehn and Yahr scale. 


\section{Cognitive impairment prevalence in PD}

Among the 901 patients, $21.4 \%(n=193)$ met the PD-D criteria recommended by the Movement Disorder Society, and $22.8 \%(n=206)$ met the criteria for PD-MCI. Overall, $44.3 \%$ of PD patients had some degree of cognitive impairment (Table 2). The cognitive assessment scores for patients with PD-D, PD-MCI, and PD with no cognitive impairment (PD-NoCI) are shown in Table 3. PD-D and PD-MCI patients performed significantly worse in nearly all the domains, compared with PD-NoCI patients. C-MMSE and MoCA global cognitive scores were significantly lower for both PD-MCI and PD-D patients. Based on the proposed cut-off value of 26 (or less) to identify cognitive impairment using both MoCA and MMSE, ${ }^{10}$ we found that MoCA could detect $86.5 \%$ of PD-D and $84.5 \%$ of PD-MCI, whereas MMSE identified just $65.3 \%$ of PD-D and $33.6 \%$ of PD-MCI (Table 4 ). Our results indicate that MoCA is more sensitive than MMSE for assessing cognitive impairment in Chinese PD patients.

\section{Cognitive deficit profiles in PD-MCI and PD-D}

We employed a set of standard cognitive tests to investigate cognitive deficit profiles in PD-MCI and PD-D patients (Table 4). In PD-MCI patients, the most common cognitive deficits were visuospatial dysfunction $(40.3 \%)$, executive dysfunction (27.7\%), memory impairment (15.0\%), and attention impairment (12.6\%). Although we used different tests to assess attention and executive function, the basic cognitive processes of these two domains cannot be clearly divided, and often overlap. For this reason, we merged the two domains for analysis purposes, and found that $83(40.3 \%)$ PD-MCI patients exhibited executive/attention dysfunction. Overall, most cognitive impairment in PD-MCI patients corresponded to visuospatial dysfunction and attention/executive impairment; only $15 \%$ of cognitive impairment in PD-MCI patients was amnestic (Table 4).

In PD-D patients, approximately $82.4 \%$ (159 patients) had visuospatial dysfunction; the frequencies of executive dysfunction, memory impairment, and attention impairment were $70.0 \%, 67.4 \%$, and $53.4 \%$, respectively (Table 4 ). When we merged the executive impairment and attention domains for analysis, 168 (87.0\%) PD-D patients had executive and/or attention dysfunction. Overall, the attention/executive and visuospatial domains were the most commonly impaired; about one-third of PD-D patients were nonamnestic.

\section{Predictive risk factors for PD-related cognitive impairment}

Among demographic factors (Table 5), having longer education and a professional career, were potentially protective factors against cognitive impairment. Males were less likely to have PD-MCI ( $\mathrm{OR}=0.63, P=0.02)$, but gender was not a significant predictive factor for PD-D (OR $=0.97, P=0.90)$. Incidence of PD-MCI was much lower in patients with selfsupport finance independency $(\mathrm{OR}=0.44, P=0.002)$, but this was not the case with PD-D (OR $=0.77, P=0.30$ ). With regard to age, PD patients who were at least 75 years old were twenty-one times more likely to develop PD-D, and four times more likely to suffer from PD-MCI $(P<0.001)$, than patients younger than 55 years. However, age at PD onset was not an influential factor.

Among clinical predictive risk factors (Table 5), cognitive impairment was associated with higher axial UPDRS impairment score, and advanced HY stages. Based on the Movement Disorder Society criteria, PD-D occurred in $12.1 \%$ of HY Stage I patients, $17.9 \%$ of Stage II patients, and $42.9 \%$ of patients at Stage III or higher. For PD-MCI, these values were $15.6 \%, 22.7 \%$, and $30.9 \%$, respectively (Stage $\geq$ III versus Stage I PD-MCI: OR $=3.97$; Stage $\geq$ III versus Stage I PD-D: $\mathrm{OR}=4.77 ; P=0.001)$. Patients with axial impairment were two times more likely to have cognitive impairment (PD-MCI: OR =2.07; PD-D: $\mathrm{OR}=2.57$; $P<0.05)$. Levodopa dosage was not a significantly influential factor. In addition, $24.4 \%(\mathrm{n}=220)$ of all $\mathrm{PD}$ patients suffered from depression, and $7.0 \%$ experienced hallucinations. In this series of patients, severity of depression symptoms was positively associated with dementia risk $(\mathrm{OR}=1.98, P=0.03$, the data was calculated in patients with Hdes-17 scores $\geq 12$

Table 2 Cognitive impairment prevalence and PD duration

\begin{tabular}{llllllll}
\hline Duration (years) & $\begin{array}{l}\text { Overall } \\
\mathbf{n = 9 0 I}\end{array}$ & $\begin{array}{l}\mathbf{0 - 2} \\
\mathbf{n = 3 0 5}\end{array}$ & $\begin{array}{l}\mathbf{3 - 4} \\
\mathbf{n = 2 2 9}\end{array}$ & $\begin{array}{l}\mathbf{5 - 6} \\
\mathbf{n = 1 3 6}\end{array}$ & $\begin{array}{l}\mathbf{7 - 8} \\
\mathbf{n = 7 9}\end{array}$ & $\begin{array}{l}\mathbf{9 - 1 0} \\
\mathbf{n = 6 4}\end{array}$ & $\begin{array}{l}\geq \mathbf{I I} \\
\mathbf{n = 8 8}\end{array}$ \\
\hline Age at admission (years) & & $63.9 \pm 10.7$ & $65.5 \pm 10.9$ & $65.4 \pm 10.1$ & $65.4 \pm 11.6$ & $66.5 \pm 9.6$ & $68.2 \pm 10.3$ \\
HY stage $\geq 3$ (\%) & & 5.9 & 15.8 & 19.8 & 37.3 & 31.0 & 55.4 \\
Dementia \% (n=193) & 21.4 & 20.7 & 15.3 & 22.1 & 19.0 & 35.9 & 30.7 \\
MCl \% (n=206) & 22.8 & 20.7 & 20.5 & 24.3 & 27.8 & 18.7 & 22.7 \\
\hline
\end{tabular}

Abbreviations: PD, Parkinson's disease; HY, Hoehn and Yahr scale; $\mathrm{MCl}$, mild cognitive impairment. 
Table 3 Cognitive test scores for patients with PD-D, PD-MCl, and PD-NoCl

\begin{tabular}{|c|c|c|c|c|}
\hline Cognition (mean \pm SD) & $\begin{array}{l}\text { PD-MCI } \\
(n=206)\end{array}$ & $\begin{array}{l}\text { PD-D } \\
(n=193)\end{array}$ & $\begin{array}{l}\text { PD-NoCl } \\
(n=502)\end{array}$ & $\boldsymbol{P}$ \\
\hline MMSE (me total) & $26.2 \pm 2.5$ & $21.9 \pm 5.3$ & $28.6 \pm 1.5$ & $<0.000$ I \\
\hline MoCA (mo total) & $20.0 \pm 4.1$ & $14.7 \pm 5.4$ & $24.9 \pm 3.2$ & $<0.000$ I \\
\hline Attention (WAIS-R Digit Span Backward) & $3.5 \pm 1.0$ & $2.7 \pm 1.3$ & $4.4 \pm 1.2$ & $<0.000$ I \\
\hline Attention (WAIS-R Digit Span total) & $10.8 \pm 2.2$ & $9.0 \pm 2.7$ & $12.4 \pm 2.2$ & $<0.000$ I \\
\hline Visuospatial (Block Design) & $22.8 \pm 10.9$ & $11.2 \pm 10.0$ & $37.0 \pm 10.2$ & $<0.000$ I \\
\hline Dysexecutive (RVR total) & $35.0 \pm 8.6$ & $25.6 \pm 10.4$ & $43.2 \pm 9.3$ & $<0.000$ I \\
\hline Dysexecutive (F words) & $6.0 \pm 3.0$ & $4.7 \pm 2.8$ & $7.2 \pm 3.3$ & $<0.000$ I \\
\hline Memory impairment (FOM initial) & $6.1 \pm 1.5$ & $4.3 \pm 2.0$ & $7.1 \pm 1.3$ & $<0.000$ I \\
\hline Memory impairment (FOM total) & $14.8 \pm 2.6$ & $1 \mathrm{I} .0 \pm 4.3$ & $16.6 \pm 1.9$ & $<0.000$ I \\
\hline
\end{tabular}

Abbreviations: PD, Parkinson's disease; PD-D, dementia; PD-MCl, mild cognitive impairment; PD-NoCl, no cognitive impairment; MMSE, Mini Mental State Exam; MoCA, Montreal Cognitive Assessment; SD, standard deviation; WAIS, Revised Wechsler Adult Intelligence Scale; RVR, Rapid Verbal Retrieve; FOM, Fuld Object Memory Evaluation.

versus patients with Hdes-17 scores $<7$ ), and patients with hallucinations were more likely to have dementia $(\mathrm{OR}=3.15$; $P<0.001)$. Clearly, cognitive impairment is associated with the severity of PD motor and neuropsychiatric symptoms in this population.

\section{Discussion}

We thoroughly and systematically investigated the prevalence of cognitive impairment in Chinese PD patients, and found that $22.8 \%$ had PD-MCI, while $21.4 \%$ met the PD-D criteria of the Movement Disorder Society. Two large studies, from Germany and Norway, have reported similar frequencies of PD-MCI (30.6\% ${ }^{11}$ and 25.8\%, ${ }^{12}$ respectively). The prevalence of PD-D described in other large studies varies greatly; a population-based study of PD patients in the Netherlands reported $22 \%$ dementia, ${ }^{13}$ and a study of 1,449 PD outpatients in Germany found that $29 \%$ exhibited dementia. ${ }^{14}$ A smaller German study (605 subjects), reported that $13.1 \%$ had dementia. ${ }^{11}$ The differences in PD-MCI and PD-D frequencies between studies are probably due to different study methods, varying criteria, and differences in disease severity. In addition, the studies mentioned above were cross-sectional, and only described point prevalence; cumulative prevalence is often

Table 4 Cognitive impairment profiles in PD-D and PD-MCl patients

\begin{tabular}{lll}
\hline & PD-D n (\%) & PD-MCI n (\%) \\
\hline Patients & 193 & 206 \\
MMSE < cut-off & $126(65.3)$ & $69(33.6)$ \\
MoCA <cut-off & $167(86.5)$ & $174(84.5)$ \\
Attention impairment & $103(53.4)$ & $26(12.6)$ \\
Visuospatial dysfunction & $159(82.4)$ & $83(40.3)$ \\
Executive impairment & $135(70.0)$ & $57(27.7)$ \\
Memory impairment & $130(67.4)$ & $31(15.0)$ \\
\hline
\end{tabular}

Abbreviations: PD, Parkinson's disease; PD-D, dementia; PD-MCl, mild cognitive impairment; MMSE, Mini Mental State Exam; MoCA, Montreal Cognitive Assessment. much greater, as has been shown in a Norwegian cohort, ${ }^{15}$ and by the Sydney Multicenter Study. ${ }^{16,17}$ For example, in the former study, the point prevalence of dementia is $26 \%$, while the 8 -year cumulative prevalence of dementia is $78.2 \% .{ }^{15} \mathrm{In}$ the latter study, the point prevalence of dementia in patients at 20 years is $83 \% .{ }^{16}$ Although it has been reported that Asian populations may have a lower incidence of dementia overall, ${ }^{18}$ our results indicate that the prevalence of cognitive impairment in Chinese PD patients is not significantly different from that observed in other races and areas.

With regard to cognitive impairment in PD-MCI and PD-D, the frequencies of memory impairment in our study are very close to those reported by others: $13.3 \%-15.1 \%{ }^{12,19}$ in PD-MCI patients, and 67.4\% in PD-D patients. ${ }^{20}$ In similarity with an earlier study, ${ }^{19}$ we found that attention/executive impairment and visuospatial dysfunction are the predominating forms of cognitive impairment in Chinese PD-MCI and PD-D patients. Memory and executive defects had been reported to be the most common impairment profiles in $\mathrm{PD} .^{21}$ Impaired attention was found to be an important aspect of cognitive impairment in PD; it is the most useful parameter to differentiate PD-D from Alzheimer's disease. ${ }^{22}$ We employed the WAIS-R scale to assess attention, because it is routinely employed by the clinics involved in this study. Although WAIS-R is usually employed to measure working memory, the capacity to maintain attention is prerequisite for completing the test. Notably, the frequency of nonamnestic domain impairment was higher in our study sample than has been reported by other studies. ${ }^{12,19}$ The different results may be due to the use of different study methods, varying degrees of disease severity, and different demographic factors. However, it may also reflect diverse patterns of neuronal degeneration associated with PD. ${ }^{23}$ A recently published hypothesis for PD proposes two different patterns of disease evolution: ie, frontal-striatal basal ganglia circuits, and posterior cortical 
Table 5 Predictive risk factors for PD-related cognitive impairment

\begin{tabular}{|c|c|c|c|c|c|c|c|}
\hline & \multirow{2}{*}{$\begin{array}{l}\text { PD-D } \\
(n=193) \\
n(\%)\end{array}$} & \multirow{2}{*}{$\begin{array}{l}\text { PD-MCI } \\
(n=206) \\
n(\%)\end{array}$} & \multirow{2}{*}{$\begin{array}{l}\text { PD-NoCl } \\
(n=502) \\
n(\%)\end{array}$} & \multicolumn{2}{|c|}{$\begin{array}{l}\text { Adjusted predictors } \\
\text { for PD-D }\end{array}$} & \multicolumn{2}{|c|}{$\begin{array}{l}\text { Adjusted predictors } \\
\text { for PD-MCI }\end{array}$} \\
\hline & & & & $P$-value & OR $(95 \% \mathrm{Cl})$ & $P$-value & OR $(95 \% \mathrm{Cl})$ \\
\hline Male & $118(61.1)$ & $113(54.8)$ & $33 \mid(65.9)$ & 0.90 & $0.97(0.59-1.59)$ & 0.02 & $0.63(0.42-0.94)$ \\
\hline Age at entry (vs < 55 years) & & & & $<0.001$ & & $<0.001$ & \\
\hline $55-64$ years & $31(16.1)$ & 41 (19.9) & $156(3||)$. & & $2.5 \mathrm{I}(1.08-5.84)$ & & $1.00(0.55-1.84)$ \\
\hline $65-74$ years & $72(37.3)$ & $79(38.3)$ & $189(37.6)$ & & $6.25(2.23-17.50)$ & & $1.57(0.69-3.60)$ \\
\hline$\geq 75$ years & 77 (39.9) & $57(27.7)$ & $53(10.5)$ & & $21.81(6.95-68.43)$ & & $4.26(1.69-10.70)$ \\
\hline Education (vs 0-6 years) & & & & $<0.001$ & & $<0.001$ & \\
\hline $7-12$ years & $84(43.5)$ & $100(48.5)$ & $221(44.0)$ & & $0.30(0.17-0.54)$ & & $0.52(0.32-0.86)$ \\
\hline$\geq 13$ years & $35(18.1)$ & $48(23.3)$ & $228(45.4)$ & & $0.15(0.07-0.31)$ & & $0.27(0.15-0.49)$ \\
\hline \multirow[t]{2}{*}{ Occupation (vs professional) } & & & & 0.02 & & 0.004 & \\
\hline & $27(14.0)$ & $4 \mid(19.9)$ & $118(23.5)$ & & $0.48(0.26-0.87)$ & & $0.49(0.30-0.79)$ \\
\hline Financially independent (vs not) & & & & 0.002 & & 0.30 & \\
\hline Yes & $124(64.3)$ & $164(79.6)$ & $434(86.4)$ & & $0.44(0.26-0.74)$ & & $0.77(0.48-1.26)$ \\
\hline Age of PD onset (vs $<59$ years) & & & & 0.73 & & 0.44 & \\
\hline$\geq 59$ years & | 37 (7|.0) & $137(66.5)$ & $254(50.6)$ & & $0.88(0.42-1.86)$ & & $1.30(0.67-2.53)$ \\
\hline Hoehn and Yahr scale (vs stage I) & & & & $<0.001$ & & $<0.001$ & \\
\hline Stage II & $100(51.8)$ & $127(61.6)$ & $333(66.3)$ & & $1.31(0.70-2.45)$ & & $1.67(0.99-2.82)$ \\
\hline Stage $\geq$ III & $72(37.3)$ & $52(25.2)$ & $44(8.8)$ & & $4.77(2.08-10.95)$ & & $3.97(1.92-8.18)$ \\
\hline Levodopa dose (vs < $400 \mathrm{mg}$ ) & & & & 0.30 & & 0.45 & \\
\hline $400-599 \mathrm{mg}$ & $32(16.6)$ & $36(17.5)$ & $102(20.3)$ & & $0.72(0.39-1.32)$ & & $0.77(0.47-1.28)$ \\
\hline$\geq 600 \mathrm{mg}$ & $56(29.0)$ & $47(22.8)$ & $78(I 5.5)$ & & $1.24(0.7 \mathrm{I}-2.18)$ & & $1.12(0.68-1.83)$ \\
\hline UPDRS axial impairment (vs not) & & & & 0.003 & & 0.01 & \\
\hline Yes & $70(36.3)$ & $50(24.3)$ & $38(7.6)$ & & $2.57(1.38-4.77)$ & & $2.07(1.17-3.69)$ \\
\hline Depression (vs Hrsd- I7 total $<9$ ) & & & & 0.03 & & 0.35 & \\
\hline (Yes: Hrsd-7 total $\geq 9,<12$ ) & $31(16.1)$ & $35(17.0)$ & $79(15.7)$ & & $1.13(0.60-2.13)$ & & $1.10(0.66-1.84)$ \\
\hline (Yes: Hrsd- 17 total $\geq 12$ ) & $88(45.6)$ & $66(32.0)$ & $107(21.3)$ & & $1.98(1.18-3.34)$ & & $1.40(0.89-2.20)$ \\
\hline Hallucinations (vs not) & & & & $<0.001$ & & 0.54 & \\
\hline Yes & $42(21.8)$ & $19(9.2)$ & $33(6.6)$ & & $3.15(1.62-6.15)$ & & $\mathrm{I} .25(0.6 \mathrm{I}-2.54)$ \\
\hline
\end{tabular}

Abbreviations: PD, Parkinson's disease; PD-D, dementia; PD-MCl, mild cognitive impairment; PD-NoCl, no cognitive impairment; OR, odds ratio; Cl, confidence interval; UPDRS, Unified PD Rating Scale; Hrsd- 17, Hamilton Rating Scale for Depression; vs, versus.

syndromes. Executive and attention defects are more obvious when the frontal-striatal pathway is involved, whereas visuospatial and memory dysfunction are more representative of posterior cortical deficits. ${ }^{24}$ In summary, the profile of cognitive domain impairment described here is similar to that reported in other races. Difference in the frequencies of domain impairment may be due to differences in methodology, racial composition, and disease evolution.

Understanding which factors can be used to predict cognitive impairment in PD is very important. We confirmed a previously reported series of potential risk factors for PD cognitive impairment in the current study. Patients with higher axial UPDRS impairment scores, HY stages, ${ }^{25,26}$ and ages $^{26-28}$ are more likely to manifest cognitive impairment. Conversely, higher educational attainment, ${ }^{4,26}$ male gender, ${ }^{28}$ professional occupation, and financial independence are, potentially, protective factors against cognitive impairment. The latter two factors may arise because receiving education is more predominant among men during economically difficult times, while better chronic disease management increased during better economic conditions. In our study, age was an influential factor for cognitive impairment in $\mathrm{PD}$, in contrast to the findings reported by Arnaldi et al. ${ }^{29}$ Although age at onset of motor symptom was not a significant influential factor, there are some studies which suggest that late-onset PD is predictive of cognitive impairment. ${ }^{27,30}$ Medications used to treat PD may affect cognition. But our study, and others, ${ }^{4,28}$ shows that the levodopa equivalent dose is not associated with the risk of cognitive impairment in PD. Hallucinations ${ }^{15,30,31}$ and depression ${ }^{26}$ have also been associated with cognitive impairment in PD patients, but these have different genetic explanations. With regard to hallucinations, one study reported that visual perception is more globally impaired in patients with PD-D than in PD-NoCI or healthy controls. ${ }^{32} \mathrm{~A}$ recent publication posited that visual hallucinations are a common feature of disorders that affect temporal lobe structures and impair ascending monoaminergic pathways. ${ }^{33}$ This provides a reasonable explanation 
for how visual hallucination is linked to cognitive decline. Depression and symptom severity are associated with cognitive impairment in PD. However, it is thought that the rate and comorbidity of depression and dementia may both be driven by the severity of PD. ${ }^{26,34,35}$ In summary, potential risk factors for cognitive impairment in the Chinese population are similar to those reported in other races.

However, there are several limitations to our study. All of our subjects were recruited consecutively from the outpatient departments of selected centers; the population may have not included some bedridden or severely disabled PD patients. With regard to the related risk factors for cognitive impairment in PD, we did not include disease comorbidity, medications other than for treatment of PD, or family history. Further studies should follow this cohort to explore cumulative prevalence and related risk factors, and focus on the progression and prognosis of cognitive impairment in PD.

In conclusion, the study aimed to explore the point prevalence and cognitive impairment profile in Chinese PD patients. Notably, it was found that MoCA is a more sensitive tool than the MMSE for identifying cognitive impairment in this population.

\section{Acknowledgment}

This study was supported by Peking Union Medical College Hospital (grant no 2006332).

\section{Disclosure}

The authors declare that they have no competing interests.

\section{References}

1. Aarsland D, Beyer MK, Kurz MW. Dementia in Parkinson's disease. Curr Opin Neurol. 2008;21(6):676-682.

2. Emre M, Aarsland D, Brown R, et al. Clinical diagnostic criteria for dementia associated with Parkinson's disease. Mov Disord. 2007;22(12): 1689-1707; quiz 1837.

3. Barone P, Aarsland D, Burn D, Emre M, Kulisevsky J, Weintraub D. Cognitive impairment in nondemented Parkinson's disease. Mov Disord. 2011;26(14):2483-2495.

4. Wu Q, Chen L, Zheng Y, et al. Cognitive impairment is common in Parkinson's disease without dementia in the early and middle stages in a Han Chinese cohort. Parkinsonism Relat Disord. 2012;18(2): 161-165.

5. Nie K, Zhang Y, Wang L, et al. A pilot study of psychometric properties of the Beijing version of Montreal Cognitive Assessment in patients with idiopathic Parkinson's disease in China. J Clin Neurosci. 2012;19(11): 1497-1500.

6. Chen W, Xu ZM, Wang G, Chen SD. Non-motor symptoms of Parkinson's disease in China: a review of the literature. Parkinsonism Relat Disord. 2012;18(5):446-452.

7. Goetz CG, Poewe W, Rascol O, et al. Movement Disorder Society Task Force report on the Hoehn and Yahr staging scale: Status and recommendations The Movement Disorder Society Task Force on rating scales for Parkinson’s disease. Mov Disord. 2004;19(9):1020-1028.
8. Fahn S, Elton RL, UPDRS program members. Unified Parkinsons Disease Rating Scale. In: Fahn S, Marsden CD, Goldstein M, Calne DB, editors. Recent Developments in Parkinsons Disease. Vol 2. Florham Park, NJ: Macmillan Healthcare Information; 1987:153-163.

9. Nasreddine ZS, Phillips NA, Bedirian V, et al. The Montreal Cognitive Assessment, MoCA: a brief screening tool for mild cognitive impairment. J Am Geriatr Soc. 2005;53(4):695-699.

10. Dubois B, Burn D, Goetz C, et al. Diagnostic procedures for Parkinson's disease dementia: recommendations from the movement disorder society task force. Mov Disord. 2007;22(16):2314-2324.

11. Balzer-Geldsetzer M, Costa AS, Kronenburger M, et al. Parkinson's disease and dementia: a longitudinal study (DEMPARK). Neuroepidemiology. 2011;37(3-4):168-176.

12. Aarsland D, Bronnick K, Williams-Gray C, et al. Mild cognitive impairment in Parkinson disease: a multicenter pooled analysis. Neurology. 2010;75(12):1062-1069.

13. de Lau LM, Schipper CM, Hofman A, Koudstaal PJ, Breteler MM. Prognosis of Parkinson disease: risk of dementia and mortality: the Rotterdam Study. Arch Neurol. 2005;62(8):1265-1269.

14. Riedel O, Klotsche J, Spottke A, et al. Frequency of dementia, depression, and other neuropsychiatric symptoms in 1,449 outpatients with Parkinson's disease. J Neurol. 2010;257(7):1073-1082.

15. Aarsland D, Andersen K, Larsen JP, Lolk A, Kragh-Sorensen P. Prevalence and characteristics of dementia in Parkinson disease: an 8-year prospective study. Arch Neurol. 2003;60(3):387-392.

16. Hely MA, Reid WG, Adena MA, Halliday GM, Morris JG. The Sydney multicenter study of Parkinson's disease: the inevitability of dementia at 20 years. Mov Disord. 2008;23(6):837-844.

17. Caviness JN, Driver-Dunckley E, Connor DJ, et al. Defining mild cognitive impairment in Parkinson's disease. Mov Disord. 2007;22(9): 1272-1277.

18. Sahadevan S, Saw SM, Gao W, Tan L, Chin JJ, Venketasubramanian N. Ethnic differences in Singapore's dementia prevalence: the stroke, Parkinson's disease, epilepsy, and dementia in Singapore study. $J \mathrm{Am}$ Geriatr Soc. 2008;56(11):2061-2068.

19. Mamikonyan E, Moberg PJ, Siderowf A, et al. Mild cognitive impairment is common in Parkinson's disease patients with normal MiniMental State Examination (MMSE) scores. Parkinsonism Relat Disord. 2009; 15(3):226.

20. Noe E, Marder K, Bell KL, Jacobs DM, Manly JJ, Stern Y. Comparison of dementia with Lewy bodies to Alzheimer's disease and Parkinson's disease with dementia. Mov Disord. 2004;19(1):60-67.

21. Muslimović D, Post B, Speelman JD, Schmand B. Cognitive profile of patients with newly diagnosed Parkinson disease. Neurology. 2005;65(8):1239-1245.

22. Bronnick K, Emre M, Lane R, Tekin S, Aarsland D. Profile of cognitive impairment in dementia associated with Parkinson's disease compared with Alzheimer's disease. J Neurol Neurosurg Psychiatry. 2007;78(10): 1064-1068.

23. Jellinger K. Post mortem studies in Parkinson's disease - is it possible to detect brain areas for specific symptoms? J Neural Transm Suppl. 1999;56:1.

24. Marder K. Cognitive impairment and dementia in Parkinson's disease. Mov Disord. 2010;25(S1):S110-S116.

25. Poletti M, Frosini D, Pagni C, et al. Mild cognitive impairment and cognitive-motor relationships in newly diagnosed drug-naive patients with Parkinson's disease. J Neurol Neurosurg Psychiatry. 2012;83(6): 601-606.

26. Riedel O, Klotsche J, Spottke A, et al. Cognitive impairment in 873 patients with idiopathic Parkinson's disease. J Neurol. 2008;255(2): 255-264.

27. Hobson P, Meara J. Risk and incidence of dementia in a cohort of older subjects with Parkinson's disease in the United Kingdom. Mov Disord. 2004;19(9):1043-1049.

28. Uc E, McDermott M, Marder K, et al. Incidence of and risk factors for cognitive impairment in an early Parkinson disease clinical trial cohort. Neurology. 2009;73(18):1469-1477. 
29. Arnaldi D, Campus C, Ferrara M, et al. What predicts cognitive decline in de novo Parkinson's disease? Neurobiol Aging. 2012;33(6):1127. e11-20.

30. Liu J, Li X, Ye J, et al. Cognitive impairments in Parkinson's disease. Aging Ment Health. 2012;16(4):529-536.

31. Galvin JE, Pollack J, Morris JC. Clinical phenotype of Parkinson disease dementia. Neurology. 2006;67(9):1605-1611.

32. Mosimann UP, Mather G, Wesnes K, O’brien J, Burn D, McKeith I. Visual perception in Parkinson disease dementia and dementia with Lewy bodies. Neurology. 2004;63(11):2091-2096.
33. Botha H, Carr J. Attention and visual dysfunction in Parkinson's disease. Parkinsonism Relat Disord. 2012;18(6):742-747.

34. Ziropadja L, Stefanova E, Petrovic M, Stojkovic T, Kostic V. Apathy and depression in Parkinson's disease: The Belgrade PD study report. Parkinsonism Relat Disord. 2012;18(4):339-342.

35. Liu Z, Chen H. Apathy and related factors in patients with Parkinson's disease. Chinese J Neurol. 2012;45(6):373-376.

\section{Publish your work in this journal}

Clinical Interventions in Aging is an international, peer-reviewed journal focusing on evidence-based reports on the value or lack thereof of treatments intended to prevent or delay the onset of maladaptive correlates of aging in human beings. This journal is indexed on PubMed Central, MedLine, the American Chemical Society's 'Chemical Abstracts

\section{Dovepress}

Service' (CAS), Scopus and the Elsevier Bibliographic databases. The manuscript management system is completely online and includes a very quick and fair peer-review system, which is all easy to use. Visit $\mathrm{http}: / /$ www.dovepress.com/testimonials.php to read real quotes from published authors.

Submit your manuscript here: http://www.dovepress.com/clinical-interventions-in-aging-journal 